\title{
Evaluation of 'Visual prostate symptom score' in men with benign enlargement of prostate in a tertiary care center in midwestern Nepal
}

\section{Dipesh Kumar Gupta}

Urology Unit, Department of Surgery, Nepalgunj Medical College, Nepalgunj.

Correspondence: Dipesh K. Gupta, Urology Unit, Department of Surgery, Nepalgunj Medical College, Nepalgunj Hospital, Nepalgunj

Email: drdipeshgupta@yahoo.com

\begin{abstract}
Introduction: Quantification of lower urinary tract symptoms (LUTS) in patients with benign enlargement of prostate (BEP) is required to initiate and regulate treatment. Among many, International Prostate Symptom Score (IPSS) is standard though it is time consuming and difficult to understand by many patients. A recent Visual Prostate Symptom Score (VPSS) which is presumed to be simpler and well understood by patients with lower educational status has been in use.

Methods: This is a prospective observational study conducted in Nepalgunj Medical College, Nepalgunj. In a total of 79 patients, 25 patients of LUTS because of other causes were excluded and 54 patients clinically diagnosed with BEP were enrolled for the study over a period of one year. Symptom evaluation was done in all with both IPSS and VPSS and uroflowmetry parameters were also recorded. The IPSS and VPSS were compared with each other and also with uroflowmetry parameters.
\end{abstract}

Results: Mean age of the patients was 67 years and mean prostate volume was $48 \mathrm{gm}$. The patients who mostly were farmers had median eighth grade of education. Fourteen were illiterates and 40 were literate patients. Significant number of patients required assistance of a medical personnel to complete IPSS $(p=<0.001)$ including those in literate group as well $(p=<0.001)$. Time taken to complete VPSS was significantly less $(\mathrm{p}=0.019)$. Total IPSS correlated with total VPSS $((\mathrm{r}=+0.36$; $\mathrm{p}=0.007)$. There was negative and significant correlation of VPSS with uroflowmeter parameters while IPSS failed to do so.

Conclusion: VPSS is an easy and reliable tool to assess symptom severity in cases of BEP presenting with LUTS. It has the added advantage of utility in assessment of LUTS in patients with lower educational status. Moreover, the patients take shorter time to complete the questionnaire.

Keywords: Benign enlargement of prostate; international prostate symptom score; visual prostate symptom score.

\section{Introduction}

Benign Prostatic Hyperplasia (BPH) is a major cause of morbidity in ageing men. ${ }^{1}$ By 60 years of age, its prevalence is greater than $50 \%$ and by age 85 , is as high as $90 \%$. Of these, between $15 \%$ and $30 \%$ men have lower urinary tract symptoms (LUTS). ${ }^{2}$ The impact of LUTS on the patient's quality of life is highly variable. However, this perception of severity determines the choice of therapy.
Measurements of prostate size and the severity of bladder outlet obstruction (BOO) correlate poorly with the severity of LUTS. Objective measurements of LUTS are key outcome measures for judging the success of treatment in clinical practice. ${ }^{3}$ Taking thorough clinical history is one established method to assess the patient's status. However, the method is not standardized and probably takes a different form for each clinician. ${ }^{4}$ 
Several validated questionnaires have evolved over time to stratify patients according to symptom severity. The American Urological Association -7 (AUA-7) symptom index, later recognized by World Health Organization as International Prostate Symptom Score (IPSS) is a validated tool with excellent test-retest reliability. ${ }^{5}$ This is a highly recommended symptom scoring tool for baseline assessment of patients with LUTS. ${ }^{6}$ This attempts to convert subjective symptoms into objective score. ${ }^{7}$ However, there are few pitfalls with its use. IPSS was supposed to be self administered with its use in primary care settings but patients with lower education level find it difficult to understand. ${ }^{8}$ Education grade of VI is considered necessary to understand the IPSS. ${ }^{9}$ There are chances of misinterpretation and misreporting if done by other family members. ${ }^{10,11}$ Furthermore, aged patients with LUTS may have visual and cognitive impairment adding to the difficulty. ${ }^{12}$ To overcome these problems Visual prostate symptom score (VPSS) has been devised by van Der Walt et al from Stellenbosch University, South Africa. It is a pictogram having four components representing weak stream, day and night frequency and quality of life. ${ }^{13}$ This is easy to use and comprehend even by patients with lower education level. ${ }^{14-16}$ It is simple, easily completed without assistance and less time taking.

Limited data is available on applicability of VPSS in a setting like ours where major proportion of the patients belongs to low socioeconomic status with low education level. Present study attempts to compare VPSS with IPSS to test its applicability in our setting.

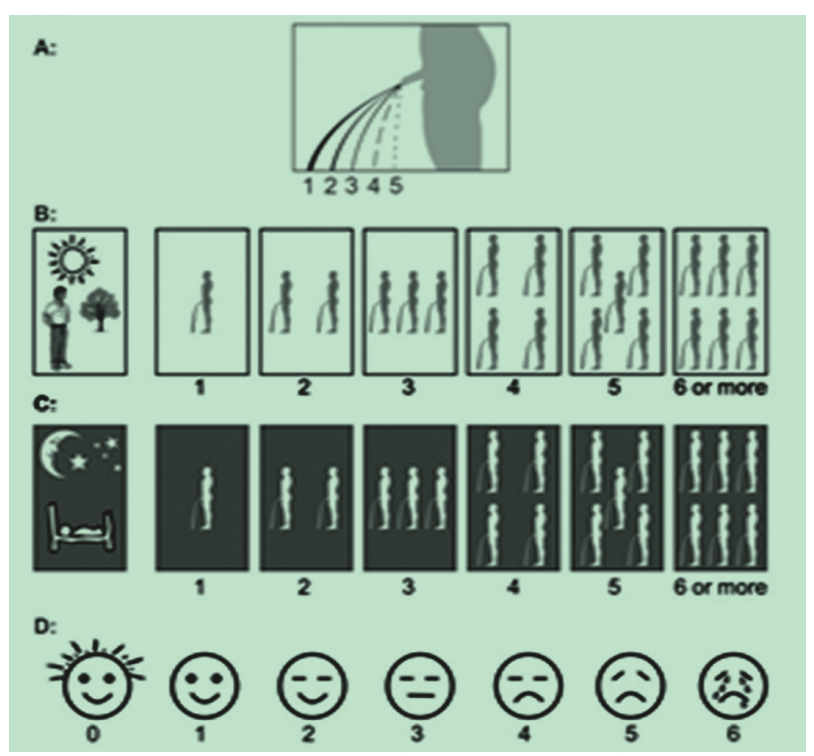

Figure 1. Visual Prostate Symptom Score

\section{Materials and methods}

This study was conducted at Nepalgunj Medical College (a tertiary care center in Mid western part of Nepal). The study enrolled 79 male patients over 40 years of age who visited the outpatient clinic during the time period of October 2014 to September 2015. Patients were requested to complete the Nepali version of IPSS questionnaire, which consists of 7 questions: Q1, incomplete emptying; Q2, frequency; Q3, intermittency; Q4, urgency; Q5, weak stream; Q6, straining; and Q7nocturia including additional question on quality of life (QoL). The total score of the IPSS was obtained by summing all 7 questions. The patients were also requested to complete the VPSS questionnaire. The VPSS consists of 4 pictograms to evaluate the following domains: Q1, force of urinary stream; Q2, frequency; Q3, nocturia, and Q4, QoL of patients.

The demographic characteristics including age, occupation, level of education, income and literacy status, were recorded. Evaluation of how the patients completed the VPSS and IPSS, with or without assistance and the time taken to complete the task were noted. Uroflowmetry parameters were taken for comparison.

The chi-square test was used for contingency table analysis to evaluate factors associated with how the respondent completed the IPSS and VPSS questionnaires. Spearman's test was used for correlation analysis between the IPSS and the VPSS. A two-tailed P-value $<0.05$ was accepted as statistically significant.

\section{Results}

Seventy nine patients with LUTS suggestive of BEP were evaluated. Twenty five patients who had LUTS because of other causes were excluded. Finally 54 patients were evaluated with IPSS, VPSS and uroflowmetry. Patient characteristics are shown in Table 1. Median duration of LUTS was 15 months. The number of patients who could read and write was 40 with eighth grade being their median grade of schooling (Figure 2). Farmers were the main patient group $(50 \%)$.

Table 1. Patients' characteristics and laboratory values

$\begin{array}{llll}\text { Variable } & \text { Mean } & \text { SD } & \text { Range } \\ \text { Age }(\mathrm{yr}) & 67 & 6.8 & 50-78 \\ \text { Prostate wt }(\mathrm{gm}) & 48.26 & 26 & 27-138 \\ \text { S. Creatinine }(\mu \mathrm{mol} / \mathrm{l}) & 94.29 & 9.9 & 75-120 \\ \text { S. PSA }(\mathrm{ng} / \mathrm{ml}) & 1.79 & 0.89 & 0.4-4.31\end{array}$




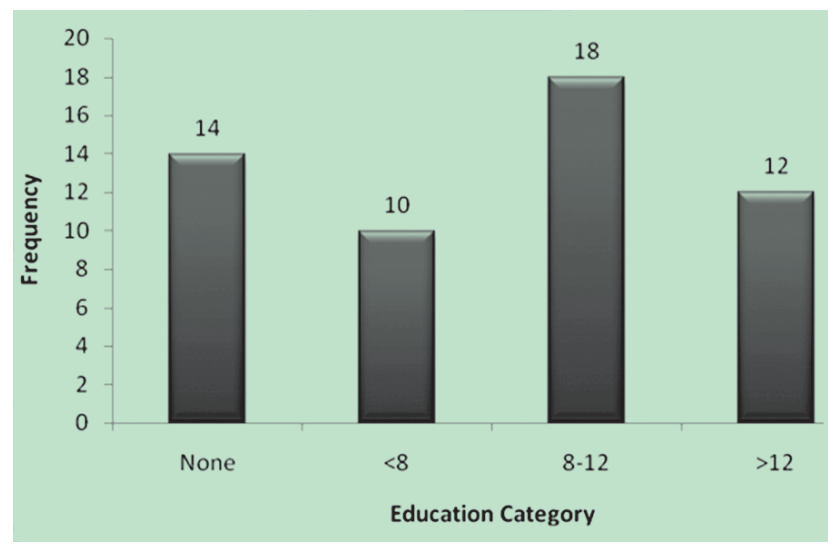

Figure 2. Educational status of the patients

Overall the patients who could complete VPSS alone without anyone's assistance was 43\%. Medical personnel had to assist in $28 \%$ of the cases. On the other hand, $76 \%$ of the cases required the assistance of a doctor while completing IPSS $(\mathrm{p}<0.001)$. In illiterate population all required assistance to fill up IPSS while VPSS could be filled in by self or family member in $50 \%$ of the cases. In literate population, filling up of VPSS required assistance of a doctor in $10 \%$ while it was $63 \%$ in IPSS group (Table 2).

Table 2. Requirement of assistance while completing IPSS and VPSS according to literacy

$\begin{array}{llll}\text { Completion by } & \text { IPSS } & \text { VPSS } & \text { p value } \\ \text { Illiterate }(\mathbf{n = 1 8}) & & & \\ \text { Alone } & 0 & 2 & \\ \text { Family member } & 0 & 6 & 0.01 \\ \text { Doctor } & 18 & 10 & \\ \text { Literate }(\mathbf{n}=\mathbf{3 6}) & & & \\ \text { Alone } & 9 & 21 & \\ \text { Family member } & 4 & 10 & <0.001 \\ \text { Doctor } & 23 & 5 & \end{array}$

Similarly, calculating time to complete IPSS and VPSS showed significant differences both in illiterate as well as literate population. Median time for completing VPSS versus IPSS was $1 \mathrm{~min} 07 \mathrm{sec}$ and $3 \mathrm{~min} 12 \mathrm{sec}$ respectively in illiterate population ( $\mathrm{p}=0.019)$, while it was $4 \mathrm{~min} 55 \mathrm{sec}$ and $1 \mathrm{~min} 54 \mathrm{sec}$ in literate population $(\mathrm{p}=0.015)$.
Mean IPSS of the patients was $23 \pm 7.5$ with mean IPSS QoL of $4.7 \pm 1.3$. Similarly, mean VPSS was $11.9 \pm 2.6$ with mean VPSS QoL of $3.6 \pm 1.6$. With median voided volume of $252 \mathrm{ml}$ in uroflowmetry, Qmax was $10.72 \mathrm{ml} / \mathrm{s}$. Post procedure ultrasonography showed a mean post void residual volume of urine of $76.73 \mathrm{ml}$.

Age correlated significantly with VPSS $(\mathrm{r}=+0.38 ; \mathrm{p}=$ $0.004)$ but failed to do so with IPSS ( $r=-0.088 ; \mathrm{p}=0.529)$. Age showed correlation with prostate weight as well $(\mathrm{r}=$ $+0.398 ; \mathrm{p}=0.003)$. Negative correlation was seen between total VPSS and Qmax $(\mathrm{p}=<0.0001)$ and Qave. Question on weak stream in VPSS (Q1) also correlated negatively with Qmax, though the result was not significant.

Importantly, there was significant positive correlation between total VPSS and total IPSS. Similarly, IPSS QoL and VPSS QoL correlated positively (Table 3).

Table 3. Spearman's correlation for IPSS and VPSS

\begin{tabular}{|c|c|c|}
\hline Parameters & $\begin{array}{l}\text { Spearman's } \\
\text { correlation } \\
\text { coefficient (r) }\end{array}$ & p value \\
\hline Total VPSS vs Qmax & -0.481 & $<0.0001$ \\
\hline Total IPSS vs Qmax & -0.117 & 0.401 \\
\hline VPSS Q1vs Qmax & -0.185 & 0.181 \\
\hline IPSS Q5 vs Qmax & -0.285 & 0.037 \\
\hline $\begin{array}{l}\text { Total VPSS vs VPSS } \\
\text { QoL }\end{array}$ & +0.417 & 0.002 \\
\hline Total IPSS vs IPSS QoL & +0.382 & 0.004 \\
\hline $\begin{array}{l}\text { Total IPSS vs Total } \\
\text { VPSS }\end{array}$ & +0.362 & 0.007 \\
\hline IPSS QoL vs VPSS QoL & +0.440 & $<0.001$ \\
\hline $\begin{array}{l}\text { Frequency VPSS vs } \\
\text { Frequency IPSS }\end{array}$ & +0.456 & 0.001 \\
\hline $\begin{array}{l}\text { Nocturia IPSS vs } \\
\text { Nocturia VPSS }\end{array}$ & +0.592 & $<0.0001$ \\
\hline $\begin{array}{l}\text { Weak Stream IPSS vs } \\
\text { WS VPSS }\end{array}$ & +0.262 & 0.056 \\
\hline
\end{tabular}




\section{Discussion}

IPSS is considered as a standard form of assessment for evaluation of patients with LUTS. Due to difficulties in completing the IPSS, new symptom scoring systems came into existence. The concept of the VPSS was based on the observation that illiterate or poorly educated men found it impossible to complete the IPSS, even with physician's assistance. In contrast, patients easily comprehended a simple diagram showing a urinating man, in which the patient can indicate the force of the urinary stream corresponding to his own (Q1 in the VPSS). ${ }^{13}$

BPH is a disease of old age. The age group of patients in this study is mostly in $60 \mathrm{~s}(42 \%)$. This is consistent with the existing literature which shows the incidence to be greater than $50 \%$ in men in their 60 s and as high as $90 \%$ by age 85. , ${ }^{2}$ In the present study, age shows positive correlation with symptom scores and prostate volume. It shows significant correlation with VPSS. Age has been well correlated with prostate volume in various studies. $1,17,18$

Educational status plays significant role while assessing patients with symptom scores. In a study in South Africa, van der walt et al found nearly one third of population to have education below seventh standard and $4.2 \%$ to have no education while evaluating with IPSS and VPSS. The literacy rate in Nepal is low with nearly $75 \%$ in male population. ${ }^{19}$ In present study, nearly $44 \%$ had education below eighth standard and nearly $33 \%$ had no education. Among illiterates, $50 \%$ of patients required assistance to complete VPSS, and $100 \%$ to complete IPSS. Among literates, VPSS could be filled in majority by patient himself, and needed assistance in $10 \%$ only, while for IPSS still majority needed some help (63\%). In the study by van der walt, patient with low education status $<7$ grade, $87 \%$ required assistance to complete IPSS and $32 \%$ to complete VPSS. In patients with more than grade 10 education, $24 \%$ required assistance to complete IPSS while only $8 \%$ to complete VPSS. ${ }^{13}$

Time consumption while completing symptom score forms is another important consideration, especially in outdoor setting. In present study, overall analysis showed that time taken to complete VPSS was significantly less as compared to IPSS. Among illiterates and literates also time consumption was significantly less in completing VPSS. This was similar to a study by Serge G. Wessels and Chris F. Heyns. ${ }^{20}$

Mean IPSS in present study was 23 with mean IPSS QoL of ${ }^{4.7}$. IPSS categorizes patients into three subgroups designating patients into mild, moderate or severe symptom group. The study categorized the majority of the patients into patients with severe symptoms. This was probably because the majority of patients were indoor patients admitted for operation. Other studies show similar results of IPSS with mean IPSS ranging from 17 to 21.7. Those undergoing operation for BEP have higher IPSS. ${ }^{21-23}$

Mean VPSS in present study was 12 with mean VPSS QoL of 3.6. Only few studies have been done to date to evaluate VPSS in LUTS and in patients with urethral stricture disease. One study had mean VPSS of 9.14

In Present study IPSS shows negative correlation with uroflowmetry parameters. However, the correlation is weak and not significant. There are certain pitfalls of uroflowmetry and the reading requires cautious evaluation for measurement errors and reading errors. Nevertheless, VPSS shows negative as well as significant correlation with Qmax. The results are similar with the studies by van der Walt and Wessels SG. ${ }^{13,20}$

Present study compares VPSS and IPSS. VPSS shows significant positive correlation with IPSS. The results are consistent with the study done by van der walt and others. ${ }^{13-16}$ Another study comparing IPSS and VPSS in patients with urethral stricture disease also shows similar positive correlation. Similarly, specific questions of IPSS related to frequency, nocturia and weak stream have also been positively correlated with the respective components in VPSS.

\section{Conclusion}

VPSS is an easy and reliable tool to assess symptom severity in cases of BEP presenting with LUTS. It has the added advantage of utility in assessment of LUTS in patients with lower educational status. Moreover, the patients take shorter time to complete the questionnaire.

\section{References}

1. Berry SJ, Coffey DS, Walsh PC, Ewing LL. The development of human benign prostatic hyperplasia with age. J Urol. 1984; 132(3):474-9.

2. Thorpe A, Neal D. Benign prostatic hyperplasia. Lancet. 2003 Apr 19;361(9366):1359-67.

3. Barry MJ. Evaluation of symptoms and quality of life in men with benign prostatic hyperplasia. Urology. 2001; 58(6 Suppl 1):25-32; discussion 
4. Donovan JL. The measurement of symptoms, quality of life and sexual function. BJU Int. 2000; 85 Suppl $1: 10-9$.

5. Mebust W RRSFVA. Correlations between pathology,clinical symptoms and the course of the disease. . Proceedings of the International Consultation on Benign Prostatic Hyperplasia Geneva: WHO. 1991:51-62.

6. Kaplan SA. Update on the american urological association guidelines for the treatment of benign prostatic hyperplasia. Rev Urol. 2006; 8 Suppl 4:S107.

7. Barry MJ, Girman CJ, O'Leary MP, Walker-Corkery ES, Binkowitz BS, Cockett AT, et al. Using repeated measures of symptom score, uroflowmetry and prostate specific antigen in the clinical management of prostate disease. Benign Prostatic Hyperplasia Treatment Outcomes Study Group. J Urol. 1995; 153(1):99-103.

8. Rodrigues Netto N, Jr., de Lima ML, de Andrade EF, Apuzzo F, da Silva MB, Davidzon IM, et al. Latin American study on patient acceptance of the International Prostate Symptom Score (IPSS) in the evaluation of symptomatic benign prostatic hyperplasia. Urology. 1997; 49(1):46-9.

9. MacDiarmid SA, Goodson TC, Holmes TM, Martin PR, Doyle RB. An assessment of the comprehension of the American Urological Association Symptom Index. J Urol. 1998; 159(3):873-4.

10. Johnson TV, Abbasi A, Ehrlich SS, Kleris RS, Schoenberg ED, Owen-Smith A, et al. Patient misunderstanding of the individual questions of the American Urological Association symptom score. J Urol. 2008; 179(6):2291-4; discussion 4-5.

11. Netto Junior NR, de Lima ML. The influence of patient education level on the International Prostatic Symptom Score. J Urol. 1995; 154(1):97-9.

12. Huh JS, Kim YJ, Kim SD. Prevalence of Benign Prostatic Hyperplasia on Jeju Island: Analysis from a Cross-sectional Community-based Survey. World J Mens Health. 2012; 30(2):131-7.

13. van der Walt CL, Heyns CF, Groeneveld AE, Edlin RS, van Vuuren SP. Prospective comparison of a new visual prostate symptom score versus the international prostate symptom score in men with lower urinary tract symptoms. Urology. 2011; 78(1):17-20.
14. Afriansyah A, Gani YI, Nusali H. Comparison between visual prostate symptom score and international prostate symptom score in males older than 40 years in rural Indonesia. Prostate Int. 2014; 2(4):176-81.

15. Ceylan Y, Gunlusoy B, Degirmenci T, Kozacioglu Z, Bolat D, Minareci $\mathrm{S}$. Is new visual prostate symptom score useful as International Prostate Symptom Score in the evaluation of men with lower urinary tract symptoms? A prospective comparison of 2 symptom scores in Turkish society. Urology. 2015; 85(3):653-7.

16. Selekman RE, Harris CR, Filippou P, Chi T, Alwaal A, Blaschko SD, et al. Validation of a Visual Prostate Symptom Score in Men With Lower Urinary Tract Symptoms in a Health Safety Net Hospital. Urology. 2015; 86(2):354-8.

17. Ganpule AP, Desai MR, Desai MM, Wani KD, Bapat SD. Natural history of lower urinary tract symptoms: preliminary report from a community-based Indian study. BJU Int. 2004; 94(3):332-4.

18. Tsang KK, Garraway WM. Prostatism and the burden of benign prostatic hyperplasia on elderly men. Age Ageing. 1994; 23(5):360-4.

19. List of countries by literacy rate [cited 2014]. Available from: http://en.wikipedia.org/wiki/CIA World Factbook.

20. Wessels SG, Heyns CF. Prospective evaluation of a new visual prostate symptom score, the international prostate symptom score, and uroflowmetry in men with urethral stricture disease. Urology. 2014; 83(1):220-4.

21. Wadie BS, Ibrahim EH, de la Rosette JJ, Gomha MA, Ghoneim MA. The relationship of the International Prostate Symptom Score and objective parameters for diagnosing bladder outlet obstruction. Part I: when statistics fail. J Urol. 2001; 165(1):32-4.

22. el Din KE, Koch WF, de Wildt MJ, Kiemeney LA, Debruyne FM, de la Rosette JJ. Reliability of the International Prostate Symptom Score in the assessment of patients with lower urinary tract symptoms and/or benign prostatic hyperplasia. J Urol. 1996; 155(6):1959-64.

23. Homma Y, Yamaguchi T, Kondo Y, Horie S, Takahashi S, Kitamura T. Significance of nocturia in the International Prostate Symptom Score for benign prostatic hyperplasia. J Urol. 2002; 167(1):172-6. 